\title{
Stakeholder engagement and participation in Uganda Oil and Gas Industry: A pitch
}

\author{
Patrick Junior ${ }^{\mathrm{a}, 1}$ \\ ${ }^{a}$ University of Queensland, Australia
}

\begin{abstract}
This paper applies (Faff, 2015, 2018) research pitching template which provides a concise and methodical approach to presenting one's research idea to a mentor/expert. Both comments and personal reflections about the pitch template has been outlined. The pitch template aids novice researcher to overcome research uncertainties and difficulties regarding their research (Wong, 2017) at same time it delivers tangible benefits (Maxwell, 2017).
\end{abstract}

Key words: Pitching Research, stakeholder management, Oil and Gas, Uganda

JEL codes: M10

\section{Introduction}

This paper applies the concept of pitching research template developed by (Faff, $2015,2018)$ to my personal research topic in Business Management. I am currently enrolled for my PhD in Business Management at University of Queensland Business School, under Management cluster. I first encountered the concept of pitching research while I attended an information session of University of Queensland pitching competition presented by Professor Faff. During the session, eleven-minute animated video was played explaining the features of the two-page pitching template and its advantages.

\footnotetext{
${ }^{1}$ Corresponding author: UQ Business School, St Lucia, Queensland 4072, email address: p.junior@business.uq.edu.au
} 
The template is such a handy tool, and this motivated me to enrol for the course, RBUS6914 Research Process in Business. More so, being in my initial stages of my $\mathrm{PhD}$, this was an opportunity to shape my research and have an engaged conversation with my supervisor about it. I did complete a handwritten pitch about my topic after the first session and this gave me confidence on how to tackle a research topic. During the first lecture, we were introduced to the pitching template and had a step by step process of filling it. we were told to find any funny fictitious topic we could pitch on. Within our group of four, we agreed on the topic "The social life of a scholar: Is having a $\mathrm{PhD}$ a blessing or a curse?". It was such a funny but interesting topic to write about. This process aides any novice researcher to understand more about the basic philosophy about pitching research template (Faff et al., 2017)

The template is simple, methodical and engaging and very helpful to the novice researcher have his/her work kick-started. In this paper, I attach the pitch for my preliminary $\mathrm{PhD}$ research idea "Stakeholder Engagement and Participation in Oil and Gas in Uganda". This paper provides an overview on how I have completed the pitching template. Also discussed in here is my personal reflection on the pitching template and concluding remarks.

\section{Brief commentary on the pitch}

Table 1 shows a summary of the Pitching template. My research question of the study is 'How can stakeholder management be improved to enhance the propensity of achieving successful Oil and gas projects execution?'. The key paper for this topic is that of Cotton, (2015). Stakeholder Perspectives on Shale Gas Fracking: A Q-method study of Environmental Discourses published in Environment and Planning A, which is an $\mathrm{A}^{*}$ journal. Cotton's paper explored the challenges the United Kingdom Government is facing regarding the shale fracking process in Lancashire, Preston city by Cuadrilla resources. The local community perceive the fracking process to be a dangerous process both socially and environmentally which is a major concern for Oil and Gas sector globally (Mardani et al., 2017; Patin, 1999).

My research idea originates from the nascent oil and gas discovery in Uganda. Uganda had its first commercial oil discovery in 2006 (Alstine et al., 2014. With the expected oil proceeds, every concerned citizen is on the watch to see what the new industry brings to the economy, hence creating a "stakeholder dilemma". Therefore, the motivation or puzzle is that, given the fact that there are more concerns most especially from the local community about social, economic and environmental issues associated with the industry, a proper stakeholder framework must be put in place. Moreover, the notion of the natural resource curse most especially in developing countries is well documented (e.g. see Frankel, 2010; 
Montague, 2002; 2009; Sala-i-Martin \& Subramanian, 2013). Having a proper stakeholder management plan is key for the success of the sector (Olander \& Landin, 2005) and benefit to the citizens and the country at large. There are various stakeholders in Oil and Gas industry with some having power, legitimacy and urgency (Mitchell et al, 1997) stake from the industry. Hence the motivation of this research is exploring how best can both the government and oil companies strike a balance for competing stakeholder interests in the nascent sector

One of the objectives of the course was to deliver a completed personal pitch and presentation thereof. Having just enrolled into my $\mathrm{PhD}$, I did face some challenges when filling the pitching template, more especially differentiating the 'idea', 'what is new?' and 'contribution'. Based on my basic research question, it was also challenging to choose the research key paper given the fact that my question has more concepts that I wanted a paper encompassing all or at least most of them. More so, I was looking for a paper with similar work in the developing country context. But after a series of practice both in class and personal exercise I go used to the template and the different parts and their implications. With exposure to previous pitches, and more literature review, I got used to the template that it become user friendly and motivating to work with. After all the processes above, I developed my personal pitch which essentially summarised what seemed to be a complex topic to a simpler, communicative and engaging one.

\section{Personal reflection}

As mentioned earlier, it was quite challenging to come up with a brief concept of my proposed $\mathrm{PhD}$ topic summarised in a more concise way. With the valuable pitching template developed by Faff $(2015,2018)$, it become so practical and engaging to have my research well communicated on a two-paged template. Most especially on the three different but which seems to be similar; "Idea", "what is new" and "contribution". The other interesting part of the template is the "other considerations', this part aided me to envisage the strengths and weakness for my proposed research. Additionally, given the nature of my topic, this section highlighted the need of collaboration with other organisations, specific for my case being the Ministry of Energy and Mineral Development, Uganda.

Finally, the Venn diagram depicting what is new in the mickey mouse (Fig. 1) which summaries the need of the research topic to have an intersection of the three overarching concepts. Specific to my research, these concepts are; oil and gas sector, stakeholder engagement and benefit realisation. In short, when stakeholder engagement is done well in the nascent oil and gas sector, and having all proceeds declared in a more transparent manner, and having both social and environmental issues addressed, the notion of the resource curse can be turned into resource blessing. 
When I was admitted, I didn't know how to communicate my research in simple terms even to my fellow colleagues, leave alone my research supervision team. But with the research pitching template, it aids the chronological description of your research. And if pitching would be made compulsory to every new higher degree by research student, it would save a great time to have one articulate easily his or her idea, even if not perfect as one would wish, research is a process which evolves over time. More so, after attending series of confirmation seminars for my colleagues, personally I would say pitching template should be adopted or incorporated for such purpose as it has most of the parameters required for confirmation. This would compress a 40-page research proposal document to 2-page without changing the original meaning at the same time communicating the message clearly to the target audience. 
Table 1. Completed 2-page pitching template on Uganda Oil and Gas Industry

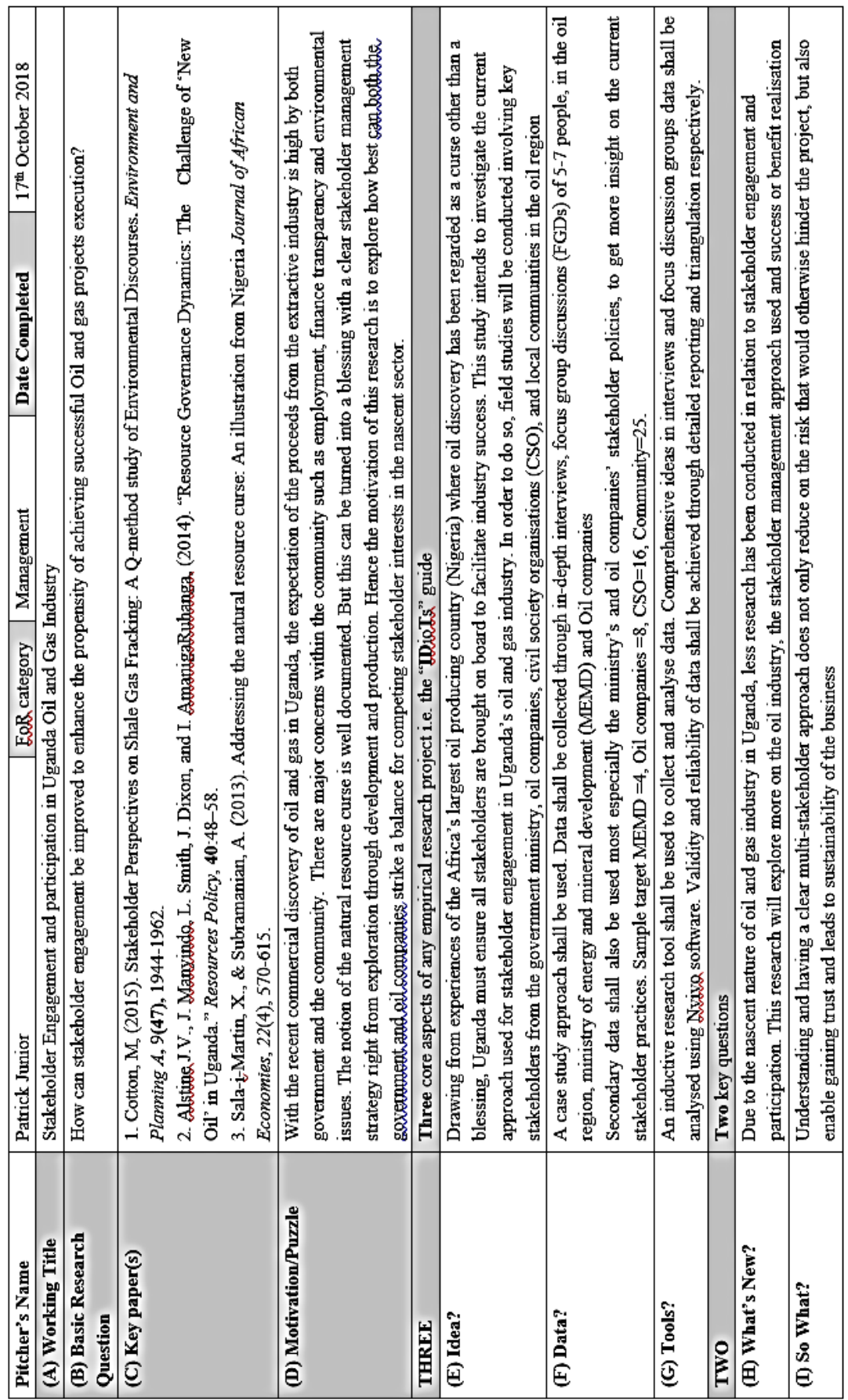




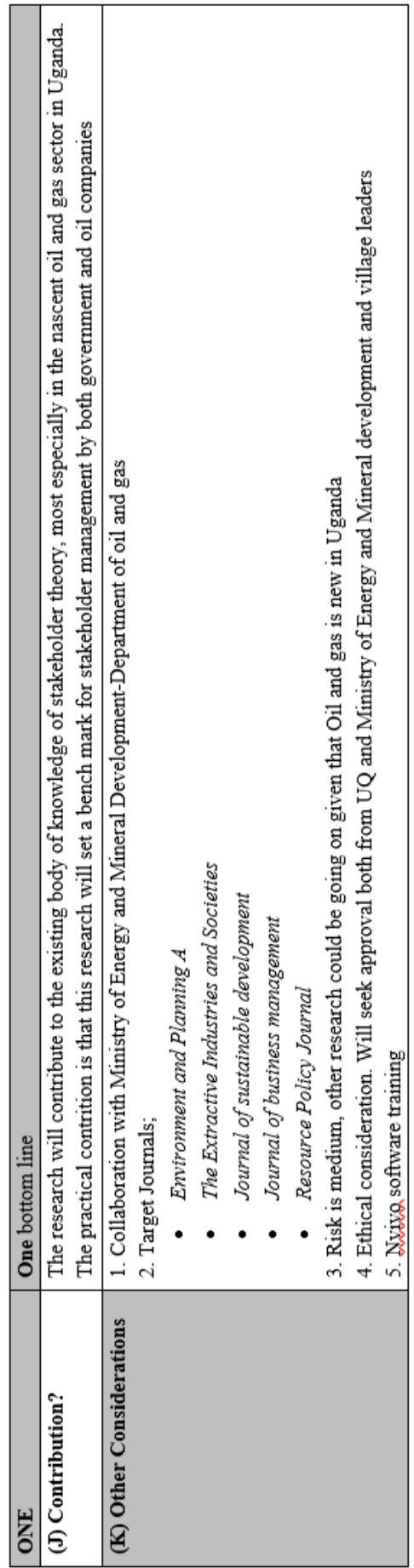




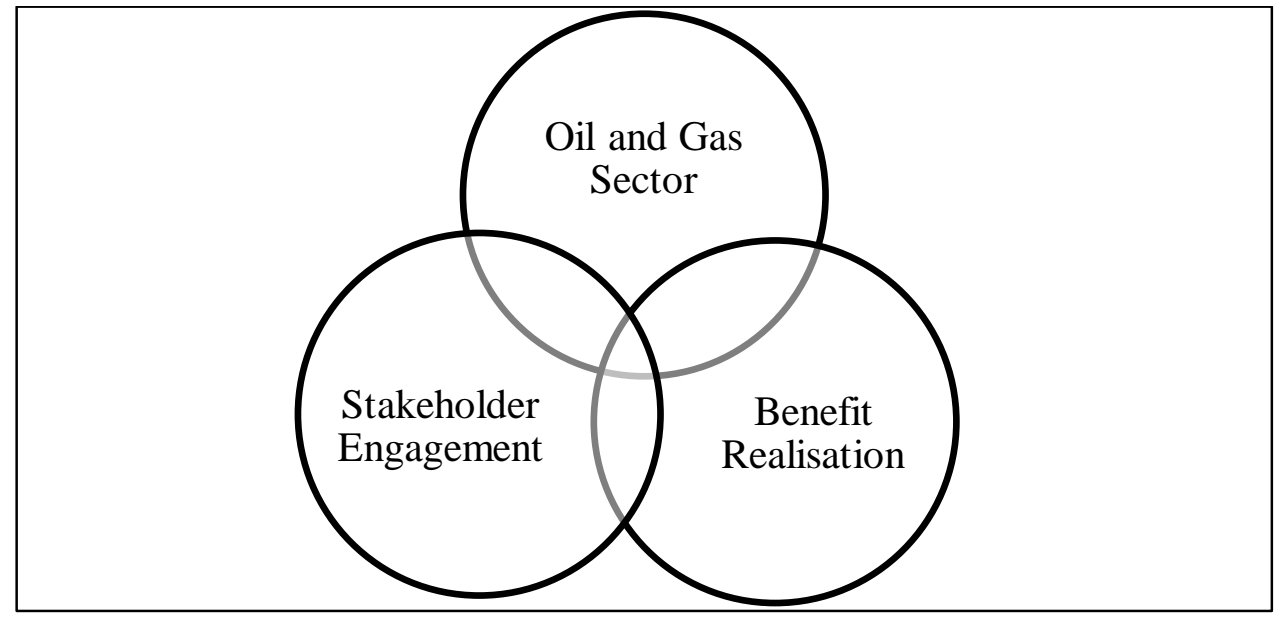

Figure 1. Mickey Mouse diagram characterizing novelty of research idea

\section{Conclusion}

This brief letter showcases an annotation and a self-reflection of the two-page research pitch template applied in Business Management whose main aim is to investigate the approaches used in stakeholder Engagement and Participation process in Oil and Gas in Uganda. It is of no doubt that research pitching template is a very handy tool for novice researchers to concisely present their research idea(s) to the potential audience. However, the pitch is not only meant for novice researchers, as it is also an important tool for the experienced researchers to showcase their research as well. Most importantly, Faff (2015) research pitch template is not discipline specific, it can be used across all areas (Faff, 2016) ranging from live sciences to humanities. In this regard, my personal advice is, every academic researcher should use this research pitch template irrespective of their research discipline and experience.

\section{References}

Faff, R. W. (2016) “The 'Pitching Research' concept: 2015, a year in review” (January 25, 2016). Available at

SSRN: https://ssrn.com/abstract=2721528 or http://dx.doi.org/10.2139/ $\underline{\text { Ssrn. } 2721528}$

Faff, R. W. (2015) “A simple template for pitching research", Accounting \& Finance, vol. 55(2): 311-336

Faff, R. (2018) "Pitching Research", Available at:

https://papers.ssrn.com/sol3/papers.cfm?abstract_id=2462059 
Faff, R., Carrick, R., Chen, A., Escobar, M.,Khong, M., Nguyen, B. \& Tunny, W. (2017) "Fantasy pitching III:UQ Summer research scholars - the role of "money" in the 21st Century", available at SSRN:https://ssrn.com/ abstract $=2906617$, DOI: $10.2139 /$ ssrn. 2906617

Frankel, J. A. (2010) "The Natural Resource Curse: A Survey," forthcoming in Brenda Shaffer, ed., Export Perils (University of Pennsylvania Press). NBER WP 15836

Mardani, A., Zavadskas, E. K., Khalifah, Z., Zakuan, N., Jusoh, A., Nor, K. M., \& Khoshnoudi, M. (2017) "A review of multi-criteria decision-making applications to solve energy management problems: Two decades from 1995 to 2015", Renewable and Sustainable Energy Reviews, vol. 71: 216-256

Maxwell, V. (2017) "Developing a research agenda through pitching", Accounting and Management Information Systems, vol. 16(2): 380-395

Mitchell, R. K., Agle, B. R., \& Wood, D. J. (1997) 'Toward a theory of stakeholder identification and salience: Defining the principle of who and what really counts", Academy of Management Review, vol. 22(4): 853-886

Montague, D. (2002) "Stolen goods: Coltan and conflict in the Democratic Republic of Congo", Sais Review, vol. 22(1): 103-118

Olander, S. \& Landin, A. (2005) "Evaluation of stakeholder influence in the implementation of construction projects", International journal of project management, vol. 23(4): 321-328

Patin, S. A. (1999) Environmental impact of the offshore oil and gas industry, East Nortport, NY: EcoMonitor Publication

Sala-i-Martin, X., \& Subramanian, A. (2013) "Addressing the natural resource curse: An illustration from Nigeria", Journal of African Economies, vol. 22(4): 570-615

Alstine, V. J., Manyindo, J., Smith, L., Dixon, J., \& AmanigaRuhanga, I. (2014) "Resource governance dynamics: The challenge of "new oil'in Uganda", Resources Policy, vol. 40: 48-58

Wong, C. (2017) "How did they make it? An examination of online personal branding: A pitch", Accounting and Management Information Systems, vol. 16(3): 413-419 